\title{
O PENSAMENTO DE JACQUES DERRIDA E SUA RECEPÇÃO NO SEIO DOS ESTUDOS JURÍDICOS: UMA ANÁLISE CRÍTICA
}

\author{
THE RECEPTION OF DECONSTRUCTION IN LEGAL STUDIES: A CRITICAL \\ ANALYSIS
}

\author{
Juliana Neuenschwander Magalhães* \\ José Antonio Rego Magalhães**
}

\begin{abstract}
RESUMO
Este artigo trata da recepção do pensamento de Jacques Derrida, conhecido sob o título de desconstrução, no seio dos estudos jurídicos. Como a recepção de Derrida nesse âmbito se deu, principalmente, na academia de língua inglesa, é por meio da discussão de uma seleção de autores de destaque nessa tradição que o presente artigo se desenvolve. Partimos da desconstrução como forma de leitura e escrita, questionando porém a possibilidade de fazer dela um método em sentido estrito. Começamos por fazer uma introdução da noção de desconstrução. Analisamos diferentes modalidades de recepção da desconstrução nos estudos jurídicos, passando pelos Critical Legal Studies e por autores de matiz mais liberal. Ao final, observamos que essa recepção, em muitos casos, incorreu em problemas, sendo ela própria passível de desconstrução. Dado isso, concluímos que a desconstrução permanece, portanto, a apresentar-se ao campo dos estudos jurídicos como desafio à frente. Chamamos finalmente atenção ao caráter marcadamente político e ético desse desafio.
\end{abstract}

\section{PALAVRAS-CHAVE}

Desconstrução. Jacques Derrida. Direito. Violência. Teoria crítica.

\begin{abstract}
This paper describes the reception of Jacques Derrida's thought, known under the title “deconstruction”, in legal studies. As the reception of Derrida's thoughts had its place mainly in English language academia, it is through the discussion of a selection of notable authors in that tradition that this paper develops. We adopted deconstruction as a form of reading and writing, while questioning the possibility of making it a method in the strict sense. We begin by introducing the notion of deconstruction. We discussed different modes of deconstruction's reception in legal studies, such as Critical Legal Studies and other, more liberal authors. Finally, we observed that this reception, in many cases, incurred in problems, becoming itself an object to deconstruct. That being given, we concluded that deconstruction therefore remains as a challenge to the field of legal studies. Finally, we call attention to the deeply ethical and political character of that challenge.
\end{abstract}

\section{KEYWORDS}

Deconstruction. Jacques Derrida. Law. Violence. Critical theory.

\footnotetext{
* Doutora em Direito pela UFMG e pela Universidade do Salento, Itália; Professora Associada da UFRJ (Rio de Janeiro, RJ, Brasil); Pesquisadora 1D do CNPq. E-mail: jneuewander@yahoo.com.br

** Mestrando pela Faculdade Nacional de Direito, Universidade Federal do Rio de Janeiro (Rio de Janeiro, RJ, Brasil). Bolsista FAPERJ. E-mail: jamagalhaes22@gmail.com
} 


\section{INTRODUZINDO - A DESCONSTRUÇÃO}

Este artigo trata da recepção do pensamento de Jacques Derrida, conhecido sob o título de “desconstrução”, no seio dos estudos jurídicos. Seu objetivo é contribuir para a difusão, já em curso, mas ainda incipiente, dessa vertente teórica no debate jurídico brasileiro por meio da revisão crítica de um determinado recorte bibliográfico. Como a recepção de Derrida no seio dos estudos jurídicos se deu, principalmente, na tradição de língua inglesa (em especial nos Estados Unidos, mas também na Inglaterra e alhures), é mediante a discussão de uma seleção de autores de destaque nessa tradição que o presente artigo se desenvolverá. Discutiremos as diferentes formas por meio das quais a obra de Derrida foi transportada às questões do direito, mantendo um tratamento crítico face a essas apropriações. Veremos que, muitas vezes, o pensamento de Derrida, cuja característica marcante está em evitar o fechamento de discursos metafísicos, acabou transformando-se em mais um desses discursos, o que acaba por mitigar seu potencial radicalmente crítico. Mantendo um grau de desconfiança frente a tais leituras, procuraremos apresentar a desconstrução como um pensamento ainda amplamente por ser explorado no âmbito dos estudos jurídicos, se levado às suas últimas consequências.

A introdução da desconstrução nos estudos jurídicos estadunidenses se deu a partir da década de 1980, quando os Critical Legal Studies (CLS) floresciam enquanto vertente crítica, transdisciplinar e afiliada, em diferentes graus, ao marxismo e à “teoria francesa”, de forma mais ou menos paralela a movimentos semelhantes, também de matriz política progressista, que vinham se desenvolvendo nos estudos literários. Na Inglaterra, desenvolvimentos da mesma ordem se apresentaram, sob, por exemplo, denominações como Critical Jurisprudence (título do livro ${ }^{1}$ de Costas Douzinas e Adam Gearey). A partir daí, também se desenvolveram no ambiente anglo-saxão outras leituras do pensamento de Derrida sobre o direito - por exemplo, em leituras de matiz “liberal”, conforme veremos.

Ao mesmo tempo, porém, que introduzimos todas essas leituras, será necessário introduzir o pensamento de Derrida “em si”, o que sempre se coloca como problema e tende a exigir, como será o caso aqui, uma aproximação um tanto oblíqua e particular. É frequente, ao escrever-se sobre a desconstrução, levantar a questão do começo: por onde começar a introduzir um pensamento que, entre suas implicações, traz a problematização de todo começo e de todo fim, e que, pelo seu próprio nome (sempre que há desconstrução, só pode ser a desconstrução de algo), já indica uma

\footnotetext{
${ }^{1}$ DOUZINAS, Costas; GEAREY, Adam. Critical Jurisprudence: The political philosophy of justice. Oxford: Hart Publishing, 2005.
} 
certa secundariedade em relação, sempre, a algum outro discurso, já é sempre um discurso de segunda ordem em relação a outro. Jeoffrey Bennington (1993, p. 15, tradução nossa) escreve:

Devemos começar em algum lugar, mas não há começo justificado. Não se pode, por razões essenciais que teremos ainda que explicar, voltar a um ponto de partida a partir do qual todo o resto possa ser construído segundo uma ordem de razões, ou segundo uma evolução individual ou histórica. No máximo, podemos dar uma justificação estratégica para o procedimento escolhido.

Rafael Haddock-Lobo (2008, p. 11), de forma semelhante, começa seu Derrida e o Labirinto das Inscrições pela questão da “porta de entrada” à obra de Derrida:

É bem difícil encontrar uma porta para se entrar nesse labirinto estranho e assimétrico - e tido por muitos como impenetrável - que se chama desconstrução. Isso porque são muitas as portas de saída e entrada, infinitas, nesse universo que não permite de modo algum qualquer sistematização precisa.

Por razões ainda a explicar - já que toda introdução vem sempre antes dos conteúdos que poderiam justificar sua forma - não há um ponto dado por onde começar a exposição da desconstrução. Ela começa, sempre, já no meio do seu caminho; pegamos sempre o bonde andando; chegamos no meio da conversa e devemos, na medida do possível, catar aqui e ali elementos para acompanhá-la. Afinal, o pensamento da desconstrução não é um sistema, uma construção que se faça sobre certas bases (se assim fosse, seria preciso começar pelos alicerces, e ir subindo, fundamentando cada elemento no anterior, como se faz nas formas sistemáticas de construção teórica). A desconstrução, é claro, não é uma construção em si, mas algo que só pode se dar a partir de alguma (outra) construção. Por isso Bennington diz que qualquer começo será estratégico: a determinação do ponto de partida da desconstrução, desse acontecimento desconstrutivo que irá se mostrar à medida que se desenrola, depende a cada vez do discurso a desconstruir-se.

Essa determinação nunca é uma escolha simplesmente livre e arbitrária. Bennington (1993, p. 15, tradução nossa) ressalta que "o lugar onde sempre começamos é sobredeterminado por estruturas históricas, políticas, filosóficas e fantasmáticas que em princípio não podem nunca ser inteiramente controladas ou explicitadas”. Sempre já nos encontramos lançados no meio de algum discurso com o qual devemos, de uma forma ou de outra, negociar. Não há uma origem certa onde começa a desconstrução, mas ela nunca se dá em um vácuo, e nunca parte de um vácuo para livremente escolher a partir de onde deverá começar. Se há uma escolha, ela é sempre negociada, constrangida.

Não seria o caso, portanto, de primeiro explicar o que é a desconstrução em si, e em seguida aplicá-la sobre um objeto jurídico. Seria preciso partir, desde já, de algum discurso jurídico (uma lei, uma doutrina, uma decisão judicial, um discurso acadêmico ou teórico relacionado ao 
direito) e, na sua desconstrução, o pensamento da desconstrução se mostraria. Por que, então, não começar de imediato? O próprio Derrida frequentemente faz longas introduções a seus textos, em que afirma estar, ainda, sem tocar seu objeto. De certo modo - e isso é, novamente, algo que ficará mais claro mais adiante - a desconstrução deve ser um pensamento paciente, nunca demasiado afoito para analisar um objeto em si mesmo, de forma direta e prática. Pedimos essa paciência ao leitor, até porque este artigo, a rigor, corre o risco de começar e terminar sem chegar à desconstrução “em si”.

Seu objetivo, como já dito, é expor como o pensamento de Derrida foi recebido em certos contextos, e, para tanto, ele trará alguns exemplos. Nos melhores deles, talvez a desconstrução se mostre. Nos piores, a desconstrução figurará transformada em instituição, estabilizada e domesticada - e aí já não se tratará propriamente de desconstrução, mas de um discurso cuja desconstrução pode fazer-se. De certo modo o que será exposto aqui não é em si mesmo um texto desconstrutivo, mas exemplos do que, até o momento, foi institucionalizado como discurso acadêmico sob o título “desconstrução”. A apresentação e análise crítica desses discursos acadêmicos (que, por vezes, talvez deva envolver uma desconstrução dos mesmos) talvez seja uma etapa necessária de uma divulgação da desconstrução em novos meios, ainda que arrisque mostrá-la como algo que, a rigor, nunca poderia ser: um discurso teórico estabilizado, institucionalizado, dotado de um método.

A rigor, o ideal seria não mais ter de tematizar a desconstrução “em si”, pelo menos em seu sentido estrito, algo que, justamente por resultar em uma recursividade vazia, muitas vezes acaba se estendendo em demasiado e, finalmente, substituindo-se à desconstrução de discursos singulares. A própria popularização do termo “desconstrução” como descrição geral, centralizante e preponderante do pensamento de Derrida não necessariamente se justifica nos seus textos, e por muitas vezes ocasionou concepções equivocadas - por exemplo, a de que a desconstrução seria redutível a um método, ou a um conjunto de afirmações teóricas ou filosóficas sobre a linguagem, a metafísica, etc. Para o pensamento do direito, muitas vezes pode ser mais interessante pensar noções como direito, justiça, soberania e violência - noções que o pensamento de Derrida permite tratar de formas inovadoras, interessantes e radicais -, do que pensar e repensar a própria noção de desconstrução. Por isso, é apenas para, mais cedo ou mais tarde, deixá-la de lado, que discutiremos aqui a noção de desconstrução. 


\subsection{O QUE DIZER SOBRE A DESCONSTRUÇÃO?}

O que dizer, então, sobre a desconstrução? Podemos dizer, por exemplo, que, antes de ser trazida por Derrida para a discussão filosófica, a palavra já se referia, em gramática, à análise de uma frase que desorganiza seus elementos a fim de preparar sua reorganização - por exemplo, para traduzi-la a uma outra língua -, e, na arquitetura, ao processo de desmanchar uma construção sem danificar suas partes, possibilitando sua reconstrução em outro lugar. Em qualquer dos dois casos, observa-se que a desconstrução difere da destruição, na medida em que está sempre ligada à reconstrução. Não é à toa que a palavra contém não apenas “des”, mas igualmente o prefixo “con”, indicando um movimento que não apenas rompe ligações, mas as reconstitui sempre em uma nova configuração. Essa nova configuração, no caso da gramática, pode se referir a uma outra ordem ou uma outra língua - a reestruturação já é uma transformação, já que nenhuma tradução é perfeita. No caso da arquitetura, a estrutura pode ser remontada em uma organização diferente ou, em todo caso, em outro lugar e, como Derrida (1972) enfatiza frequentemente, essa mudança de contexto já impede que a repetição possa se dar sem que represente, ao mesmo tempo, uma alteração.

No percurso de Derrida, a palavra “desconstrução” aparece pela primeira vez quase por acaso, como tradução de um termo de Heidegger: “der Abbau”. Para Lèbre (2013, p. 8) trata-se de uma tradução justa, na medida em que o "ab” corresponde ao "dé” do francês (e portanto ao "des” do português), e "Bau” corresponde a “construção"; tanto o elemento relativo à ruptura quanto o relativo à reconstrução aparecem lado a lado.

Essas digressões sobre a palavra são iluminadoras do que está em discussão, e ainda assim não fornecem nenhuma definição de desconstrução. Isso seria suficiente e, ao mesmo tempo, não seria, já que, logo adiante, devemos passar a uma revisão bibliográfica que, de certo modo, trará discursos sobre alguma coisa chamada “a desconstrução" que é trazida ao campo jurídico. Deveríamos, então, ensaiar alguma definição da desconstrução, mesmo sendo essa uma empreitada impossível de concluir? Talvez sim, mesmo que, da mesma forma que as proposições que formam o ponto 6. do Tractatus de Wittgenstein, elas possam revelar-se, mais adiante, como frases sem sentido formando uma escada que, uma vez usada para chegar a um certo ponto, deva ser descartada ${ }^{2}$.

\footnotetext{
2 “6.54. Minhas proposições servem como elucidações da seguinte forma: quem quer que entenda o que estou dizendo eventualmente as reconhecerá como sem sentido, quando as tiver usado - como degraus - para escalar para além delas. (Ele deve, por assim dizer, jogar a escada fora após tê-la escalado).” (WITTGENSTEIN, 1974, p. 89, tradução nossa)
} 
Vejamos duas dentre as aparições iniciais da desconstrução na obra de Derrida, em seus dois livros mais conhecidos e que deram o impulso primordial à sua carreira filosófica, De la Grammatologie e L'écriture et la différence, ambos de 1967:

Os movimentos de desconstrução não forçam [ne sollicitent] as estruturas a partir do lado de fora. Eles não são possíveis nem eficazes, nem podem ajustar sua mira, a não ser habitando essas estruturas. Habitando-as de uma certa maneira, já que sempre habitamos, e mais ainda quando não nos damos conta disso. Operando necessariamente a partir do interior, pegando emprestados da antiga estrutura todos os recursos estratégicos e econômicos da subversão, e pegando-os emprestados estruturalmente, isto é, sem poder isolar seus elementos e átomos, a empresa da desconstrução, de certa forma, é sempre carregada pelo seu próprio trabalho [emportée par son propre travail]. (DERRIDA, 1967a, p. 39, tradução nossa)

Mas se ninguém lhe pode escapar, se ninguém é, portanto, responsável de ceder [à tradição], por pouco que seja, isso não quer dizer que todas as maneiras de ceder sejam de igual pertinência. A qualidade e a fecundidade de um discurso se medem talvez pelo rigor crítico com o qual é pensada essa relação com a história da metafísica e aos conceitos herdados. Trata-se aí de uma relação crítica com a linguagem das ciências humanas e de uma responsabilidade crítica do discurso. Trata-se de colocar expressamente e sistematicamente o problema do estatuto de um discurso que pega emprestados de uma herança os recursos necessários à desconstrução [a palavra aparece aqui separada por hífen - dé-construction] dessa mesma herança. Questão de economia e de estratégia. (DERRIDA, 1967b, p. 414, tradução nossa)

O que essas passagens - retiradas, diga-se, um tanto violentamente do seu contexto (que, de todo modo, não constituía um discurso propriamente sobre a desconstrução) - nos dizem da desconstrução? Antes de tudo, definições negativas: a desconstrução não ataca, não exerce sua força a partir de um lado de fora. Ela não conta com nenhum recurso que não pertença desde já à própria tradição, à própria estrutura que a desconstrução habita, que ela desconstrói habitando. E, por isso mesmo, ela é sempre levada por diante pelo seu próprio trabalho, não podendo predeterminar para si uma finalidade (para tanto, seria sem dúvida necessário algum ponto de apoio exterior à estrutura). Ao mesmo tempo, esse fato - de que a estrutura, a tradição, a herança são inescapáveis não implica que todas as maneiras de participar dessas estruturas sejam iguais. Mas, até aqui, não se sabe nada sobre o que é isso que se dá sempre dentro de uma tradição, a partir dos seus recursos. A parte mais positiva vem ao fim da segunda passagem: trata-se de sistematicamente recolocar o problema do estatuto de tal discurso, de tal herança, cujos recursos usam-se para tanto.

Isso é o que poderia se chamar de uma definição da desconstrução? Apenas em termos muito enviesados. Deixemos, porém, esses recursos de lado por ora. Em geral, as definições mais diretas, práticas, straightforward ${ }^{3}$ da desconstrução não vêm de Derrida, mas dos comentadores da sua obra, e em especial daqueles que, atuantes em outras áreas que não a filosofia, desejariam

\footnotetext{
${ }^{3}$ A pertinência da palavra inglesa já diz sobre uma certa tendência do pensamento anglo-saxônico, relacionada ao pragmatismo e à simplicidade, que exerce seus efeitos, como veremos ao longo deste trabalho, sobre a recepção da desconstrução em terras norte-americanas.
} 
capturar a desconstrução como algo de que possam lançar mão, aplicando-a bem ou mal às respectivas áreas de estudo. Transcrevemos a seguir dois trechos sobre a desconstrução, mais breves e mais acessíveis, por um dos seus divulgadores no âmbito acadêmico norte-americano de estudos jurídicos, Michel Rosenfeld (1992, p. 152-153, tradução nossa). O primeiro é, como o que vimos até aqui, de teor mais negativo, embora inclua uma proposição geral que, segundo o autor, faria parte de uma mensagem da desconstrução. No segundo, a desconstrução aparece mais como um conjunto de afirmações teóricas sobre a escrita.

\begin{abstract}
A desconstrução parece esposar a proposição de que a aplicação de regras jurídicas e doutrina está destinada a levar ao conflito, à contradição e à indeterminação. Qualquer tentativa de definir a desconstrução é no mínimo arriscada, já que há discordância sobre se a desconstrução é um método, uma técnica ou um processo baseado em uma dada visão ontológica ou ética.
\end{abstract}

[De acordo com a desconstrução], toda escrita incorpora uma tentativa falhada de reconciliar identidade e diferença, unidade e diversidade, o mesmo e o outro; uma escrita pode dar a impressão de ter chegado à reconciliação desejada, mas tal impressão pode apenas ser o produto de distorção, supressão ou diferença ideológica ou subordinação do outro.

Deixemos, por ora, de discutir em profundidade a maior ou menor pertinência desses discursos sobre a desconstrução. Eles nos servem como definições ad hoc das quais precisamos para observar a recepção da desconstrução nas instituições acadêmicas jurídicas estadunidenses e inglesas. A partir deles, já situamo-nos mais claramente dentro de uma tradição, já temos uma herança com cujos recursos podemos jogar, e por enquanto isso é suficiente para que continuemos avançando um discurso sobre essa tradição.

Rosenfeld nos lembra de que há discordância sobre se a discussão é um método, uma técnica, ou um processo. Não está claro se ela deve ser necessariamente uma dessas coisas, ou se há a opção de que não seja nenhuma delas. Preferiríamos a segunda interpretação, já que dentre as definições negativas que se pode dar da desconstrução, eis uma das importantes: ela não é um método, não é uma forma de razão crítica, não indica um protocolo de leitura. Em qualquer desses casos, já não se trataria da desconstrução de um discurso, mas justamente de um discurso estruturado a partir dos seus próprios pressupostos. Todo método deve indicar um conjunto de procedimentos capazes de garantir um certo resultado; toda crítica depende de uma racionalidade que a fundamente; todo protocolo de leitura indica um mapa a priori que nos permita engajar-nos com um texto, seja qual for. A desconstrução, como vimos, deve dar-se exclusivamente a partir do discurso a desconstruir, nunca trazendo sobre ele um arcabouço exterior a ser aplicado, e nunca orientada a um fim pressuposto. Nesse sentido - retomando a metáfora topográfica de HaddockLobo (2011, p. 13) - é que a desconstrução pode ser descrita como "um novo pensamento que não 
pretende mais sair do labirinto mas, ao contrário, ir cada vez mais alargando as dimensões labirínticas do pensamento, ou seja, ao contrário da postura tradicional da filosofia, não se orientar conscientemente."

Haddock-Lobo diz dever essa expressão - “não se orientar conscientemente” - a seu professor Paulo César Duque-Estrada, que, segundo ele, tinha o costume de aludir "a esta nãoorientação consciente como a lúcida tarefa à qual os que se pretendem (in)fiéis a um pensamento desconstrutor devem dedicar-se”. Com efeito, para Duque-Estrada (2004, p. 63), “o pensamento desconstrucionista é, antes, um pensamento conscientemente desorientado, e só assim, segundo Derrida, verdadeiramente responsável.” Afinal, quem simplesmente aplica um protocolo ou método predeterminado não pode ser responsável pelo que pratica. Apenas um pensamento desorientado que, como vimos, é levado adiante pelo seu próprio trabalho - pode chegar a algo novo, desestabilizando as estruturas e tradições em que se desloca.

É essa necessária ausência de qualquer conteúdo, diretriz, método, finalidade ou utilidade prática que torna um tanto vazia qualquer discussão sobre a desconstrução que não seja, antes, a discussão de alguma outra coisa. A desconstrução deve introduzir-se em uma tradição - ou melhor, está sempre já introduzida em uma - para atuar. Tendo, então, feito esse percurso inicial de introdução, esse movimento duplo que, por um lado, quis esboçar uma definição da desconstrução e, por outro, reservar a ela um espaço de mistério, passaremos desde logo à sua introdução em uma tradição - a desconstrução no pensamento jurídico.

\section{A RECEPÇÃO DA DESCONSTRUÇÃO NO SEIO DOS ESTUDOS JURÍDICOS DE LÍNGUA INGLESA}

Embora Derrida estivesse ativamente envolvido no momento do pensamento francês dos anos 1960-70, juntamente com autores como Michel Foucault, Gilles Deleuze, Jean-François Lyotard e Jacques Lacan, sua recepção na França sempre foi conturbada. Foi a partir dos anos 1970 e 1980, e em outro continente, a América, que sua obra, agora sob a alcunha “desconstrução”, encontrou uma maior aceitação, e não tanto no âmbito da Filosofia, em que a hegemonia da filosofia analítica, representada por filósofos como John Searle, era capaz de gerar grande animosidade à sua figura, mas no âmbito principalmente dos estudos literários, em que a "French theory” vinha juntar-se a um certo marxismo para gerar vertentes críticas dedicadas a rever o cânone literário no ímpeto politicamente engajado de mitigar a opressão da tradição sobre grupos subalternos (mulheres, negros, LGBT). A mesma onda crítica, engajada a um projeto político 
progressista, manifestou-se também na teoria jurídica, principalmente sob a forma dos Critical Legal Studies, e foi então que Derrida viu sua obra amplamente lida por acadêmicos de Direito.

No contexto norte-americano, porém, pode-se dizer (como procuraremos mostrar em seguida) que a obra de Derrida nem sempre foi bem interpretada, não só por seus detratores, mas inclusive por aqueles que entusiasmadamente abraçavam a desconstrução. Estes, como veremos, ora a receberam como uma arma poderosíssima, capaz de ser brandida contra todas as opressões em nome de um projeto político predeterminado, ora a adaptaram ao pensamento jurídico (liberal) de forma a despojá-la de toda sua força, domesticando-a. O que tornou-se tão amplamente conhecido, aclamado, odiado como “a desconstrução” é então, pretendemos afirmar, em grande medida uma série de caricaturas do pensamento de Derrida, de tal modo a fazer-se necessária uma cautelosa reconsideração dessa recepção, evitando assim pontos de partida que podem ser pouco profícuos.

Ressaltamos, porém, desde já (e conforme será esclarecido mais adiante), que não se trata aqui de estabelecer uma prerrogativa de originalidade e pureza da obra de Derrida ou da desconstrução - coisa que seria avessa à índole da própria desconstrução. Trata-se, antes disso, de submeter as leituras aqui analisadas da desconstrução ao próprio teste desconstrutivo, isto é, observar onde os discursos ali produzidos procuram solidificar-se e institucionalizar-se em torno de certos pressupostos, e mostrar a instabilidade desses pressupostos. $\mathrm{O}$ compromisso assumido por esses discursos e aquilo que eles próprios chamam de desconstrução é, é claro, um dos principais elementos nesse jogo de institucionalização e desestabilização. Por isso, acreditamos não se tratar, aqui, de uma crítica que poderia ser chamada de simplesmente "externa” a essas leituras da desconstrução, como tampouco, também é claro, de uma crítica puramente “interna” a esses discursos. Em primeiro lugar porque, tratando-se de discursos que se pretendem como leituras de certos textos sob a etiqueta “desconstrução”, uma crítica “interna” a essas teorias não poderá excluir da sua análise (lá em que se estabelece a separação entre “dentro" e “fora”) os próprios textos de Derrida, isto é, alguma leitura desses textos, que é o que até agora oferecemos. Em segundo lugar porque, como a crítica proposta aqui a esses textos é, ela mesma, desconstrutiva, ela própria deve complicar a distinção entre uma crítica “interna” e "externa” de qualquer discurso, já que a desconstrução nunca é puramente interna nem externa a um discurso (DERRIDA, 2002).

Nesse sentido, o recente livro de Jacques de Ville, Law as Absolute Hospitality, fornecenos uma análise rigorosa e crítica - por vezes bastante agressiva em seu estilo - da recepção de Derrida no Direito. Para de Ville (2011), Derrida é apresentado ao âmbito jurídico pelos seus defensores como um pensador extremamente radical e original, mas, a seguir, descrito em termos que não traduzem sua verdadeira potência de desestabilização - domesticam seu pensamento, 
tornando-o quase impossível de discernir de outros discursos teóricos já existentes sobre o direito. Tanto a recepção negativa quanto a positiva de Derrida se caracterizariam por "uma falta de apreciação ou desprezo [disregard] por seu projeto mais amplo" e "uma falta de rigor teórico [rigorous scholarship]” (DE VILLE, 2011, p. 2, tradução nossa). Essa falta de rigor resultaria em leituras que de Ville considera “metafísicas” do pensamento de Derrida - leituras que já não conservam seu caráter desconstrutivo, e sim fazem da desconstrução mais um discurso, mais um método, e muitas vezes - inadvertidamente - mais uma forma de manutenção do status quo jurídico.

Fazer uma interpretação metafísica de Derrida, como frequentemente acontece no contexto jurídico, pode sem dúvida representar algum benefício para o direito, e em última instância para a comunidade servida pelo direito. Isso, porém, é precisamente o problema com esse argumento. O projeto derridiano de exceder a metafísica não está preocupado em primeiro lugar com o fortalecimento do direito ou da comunidade, mas precisamente com a suspensão do direito e, junto a ela, com a autoimunidade (ou pulsão de morte) da comunidade servida por esse direito. (DE VILLE, 2011, p. 8, tradução nossa)

Peter Goodrich (2009) relaciona semelhante domesticação do pensamento de Derrida ao seu caráter especialmente ameaçador ao common law. Isso se deveria ao fato de que tal pensamento (que Goodrich prefere chamar "gramatologia” a “desconstrução”) levantaria a suspeita de que haja um elemento de violência, arbitrariedade e força na imposição do precedente sobre relações sociais já muito diferentes daquelas em cuja presença a inscrição original do direito teria se dado. Goodrich (2009, p. 260, tradução nossa) contrasta, ainda, a tradição protestante (pragmática, imediatista) dos países de língua inglesa com a tradição judaica representada, segundo ele, pelo pensamento de Derrida:

\footnotetext{
Da forma como reconstituí a política da sua recepção no interior da academia jurídica, [Derrida] escreve dentro de, e frequentemente criticamente ou contra, uma tradição talmúdica de cultura e pensamento. Sua preocupação com a profundidade semântica e polissemia das palavras, a forma como ele joga com a indeterminação e com a paciência do intérprete, e a sua suspensão do juízo em particular pertencem a uma tradição de pensamento não instrumental e profundamente espiritual. A vita activa protestante, por outro lado, é voltada à decisão, a atos viris e externos, à evasão da filosofia, e também aos modos de interpretação que encorajam conclusão - um fim às palavras e uma entrada no mercado.
}

Ademais, Goodrich (2009, p. 278, tradução nossa) aponta que o pensamento jurídico, preocupado com sua independência em relação a outras disciplinas (uma questão, finalmente, ligada à soberania), seria avesso ao potencial do pensamento "gramatológico" de "explicitar o fato de que o direito é sempre já hospedeiro de outras disciplinas”. Goodrich argumenta que, “estudado como uma forma de inscrição, um sistema de escrita, força ou performance [...], o direito teria que ser 
tratado explicitamente como um híbrido, como uma coleção heterogênea de linguagens e outros sistemas de significação.”

Acusações como as recém-trazidas por de Ville e Goodrich - de que o âmbito do direito tenderia a domesticar o pensamento da desconstrução como uma reação ao potencial que tal pensamento teria de desestabilizar seus pressupostos mais fundamentais - dirigem-se, é claro, a leituras mais "liberais" (no sentido norte-americano) que, ao falhar em traduzir a radicalidade e a capacidade de abalo institucional do pensamento de Derrida, transformam-no em mais um pensador liberal do direito, adaptável à boa consciência das instituições jurídicas. Elas não se aplicariam igualmente aos Critical Legal Studies, por exemplo, que se empenham em extrair da desconstrução ferramentas para revolucionar tais instituições. Justamente, porém, nesse ímpeto de subordinar a desconstrução a um projeto político “progressista” (a própria noção de progresso poderia ser trazida aqui ao debate), também os Critical Legal Studies arriscam devolvê-la a um fechamento metafísico, de tal forma que o próprio potencial desconstrutivo desses discursos corre sério risco de ser comprometido - pelo menos se levarmos o pensamento de Derrida seriamente, e pareceria estranho adotá-lo sem levar a sério suas implicações teóricas.

Jack Balkin (2005, p. 734, tradução nossa) critica a apropriação da desconstrução pelos Critical Legal Studies, argumentando que, se, de acordo com o pensamento da desconstrução, os discursos jurídicos são indeterminados, também os discursos políticos o são. Assim, para Balkin, seria impossível o argumento dos Critical Legal Studies no sentido de que a política, e não os argumentos jurídicos, determinava as decisões judiciais. Além disso, o autor argumenta que "a ideia de que os juízes poderiam manipular a linguagem indeterminada do direito [em nome de interesses políticos] parece pressupor um sujeito jurídico autônomo no controle de suas próprias crenças”. Para a desconstrução, porém, os sujeitos não são menos "socialmente construídos" ou “indeterminados” do que a linguagem do direito, de modo que Balkin pode argumentar, sem estar errado, que "a linguagem do direito constrói a consciência e molda o pensamento dos acadêmicos de direito e juízes tanto quanto as categorias da política [e dos demais campos sociais] o fazem”.

A partir de tais considerações, Balkin (2005, p. 739, tradução nossa) argumenta que esse uso “crítico” (“metodológico”, diríamos) da desconstrução torna-se o que ele chama de uma forma “transcendental” da desconstrução, na medida em que ela "pressupõe a existência de valores humanos transcendentais”. Diríamos, em outras palavras, que, ao transformar-se em um método dirigido a certos fins, e ao pressupor uma preponderância da política ou do sujeito sobre outros discursos (como se a política e o sujeito que decide não fossem discursos tão indeterminados e 
desconstrutíveis quanto quaisquer outros), essa leitura da desconstrução recairia necessariamente em algum tipo de fechamento metafísico.

Assim argumenta de Ville (2011): os Critical Legal Studies instrumentalizam o pensamento de Derrida de forma a transformá-lo em um método, recaindo necessariamente no campo da metafísica. Ele ressalta, contudo, que isso não é necessariamente ruim do ponto de vista político, mas apenas do teórico. De fato, isso só poderia ser considerado um erro, do ponto de vista da estratégia política, se tomássemos como ponto de partida que a desconstrução seja mais efetiva politicamente do que outras matrizes teóricas. Isso, é claro, não está dado e poderia ser longamente discutido.

Em sua discussão no New York Times sobre a recepção da "French theory" - e em especial da desconstrução - nos Estados Unidos, Stanley Fish (2008) argumenta que a desconstrução não teria quaisquer consequências políticas necessárias, e não poderia ser associada essencialmente nem a uma agenda progressista, nem conservadora. Fish (2008, documento não paginado, tradução nossa) argumenta:

\begin{abstract}
Quando uma análise desconstrutiva interroga uma aparente unidade e descobre, como sempre descobrirá, que a sua coerência superficial se faz possível através da supressão de certas questões que ela não pode levantar se pretender manter a ficção da sua autoidentidade, o resultado não é a descoberta de uma anomalia, de um desvio da norma que pode ser banido ou corrigido, já que nenhuma estrutura construída pelo homem (isto é, nenhuma estrutura em geral) poderia ser diferente disso.
\end{abstract}

Segundo Fish (2008, documento não paginado, tradução nossa), “nenhuma conclusão normativa - 'tal é ruim’, ‘tal deve ser deposto’ - pode ser extraída de que algo é uma construção social $^{4}$, já que para a lógica do pensamento desconstrutivo tudo é uma construção social”. Com efeito, uma clara implicação do pensamento de Derrida é que todas as estruturas podem ser desconstruídas, o que pode ser expresso na ideia de que toda estrutura é uma construção social (ou discursiva). Disso decorre, é claro, que nenhum sistema é condenável pelo simples fato de ser uma construção. A desconstrução, então, se concebida como método capaz de mostrar certas instituições como injustas e dignas de serem rejeitadas, seria uma impossibilidade do ponto de vista teórico.

Fish (2008, documento não paginado, tradução nossa) acrescenta, contudo, que "isso não significa que uma construção social não possa ser criticada, apenas que ela não pode ser criticada por ser uma construção social”. Não está dado, porém - e isso parece ser algo que Fish não leva em

\footnotetext{
${ }^{4}$ Fish usa a expressão “construção social” como forma de apresentar mais sucintamente seu pensamento (afinal, escreve no contexto de um artigo para a imprensa), mas, a rigor, Derrida dificilmente usaria tal expressão, já que ela implicaria uma preponderância do social ou uma concepção fundamental de sociedade. Para dialogar a partir de Fish, continuamos a adotar a expressão neste trecho, embora talvez fosse melhor dizer “construção discursiva” ou usar de formulações mais oblíquas.
} 
conta - que a forma como a desconstrução surte suas consequências políticas seja a) mostrando que uma estrutura é uma construção social e b) condenando-a politicamente nessa base. Como pensado por Derrida, o trabalho da desconstrução não se divide nessas duas fases, e não tem a rigor nada a ver com a condenação de uma instituição. De todo modo, a oposição de Fish (2008, documento não paginado, tradução nossa) ao uso da desconstrução para finalidades políticas procede no sentido de que "apenas parando o questionamento e congelando o que Derrida chamou do jogo sem fim dos significantes é que se pode transformar a desconstrução em um método de ação política, e nesse ponto já não se trata de desconstrução, mas de mais uma posição desconstrutível”. Nesse sentido, seria necessário distinguir, de um lado, a ideia de que o pensamento de Derrida seja politicamente consequente (no que acreditamos) e, de outro, a ideia de que essa consequência política seja atingida mediante sua instrumentalização para um fim.

Simon Critchley (2008, p. 21, tradução nossa) demonstra semelhante ceticismo diante da interpretação da desconstrução como "um desfazimento metodológico de oposições binárias (fala/escrita, homem/mulher, dentro/fora, razão/loucura, etc.)”. Para Critchley,

[...] essa é uma prática que levou gerações inteiras de estudantes de ciências humanas para o cul-de-sac intelectual de localizar oposições binárias em textos supostamente canônicos e epifenômenos culturais e, então, incansavelmente desconstruí-las em nome de uma posição vagamente política de alguma forma considerada progressista. Na medida em que o nome de Derrida e excertos antologizados e só meio-entendidos de alguns de seus textos foram mobilizados para tal causa, isso apenas levou à redução da desconstrução a algum tipo de método inteiramente formalista baseado em uma filosofia da linguagem não provada.

Esta última afirmação - de que a filosofia da linguagem em questão não teria sido provada - não é um ataque à filosofia de Derrida. Apenas quando a desconstrução é proposta como método a ser aplicado de fora para dentro sobre textos é que ela precisaria, então, de uma filosofia da linguagem. Ela teria que dizer, por exemplo, "todo texto é feito de oposições binárias que funcionam de tal e tal maneira e podem ser desfeitas de tal e tal forma” - uma afirmação geral sobre a natureza da própria linguagem. A desconstrução, porém, justamente por começar novamente a partir do interior de cada texto, não tem nenhuma filosofia geral da linguagem, até porque o conceito de linguagem, em Derrida, é recolocado por meio do conceito de escritura. A desconstrução de cada novo texto deve ser singular, diferente da desconstrução de qualquer outro texto - ainda que desconstruções de textos inseridos dentro de uma mesma tradição e ligados de alguma forma apresentem, é claro, traços comuns.

Para melhor sistematizar e ultrapassar aquilo que estamos discutindo, voltemos a de Ville, que apresenta o que, segundo ele, são as quatro modalidades básicas da recepção de Derrida no 
mundo anglófono: uma leitura metodológica, uma leitura pós-moderna ${ }^{5}$, uma leitura ético-liberal e uma leitura cosmopolita. A leitura metodológica é a que acabamos de discutir - a desconstrução como um método a ser aplicado de fora para dentro sobre algum objeto. Para de Ville (2011, p. 4), essa leitura se perde por "reter uma distinção entre a linguagem, de um lado, e a realidade (social) de outro.” Segundo o autor, a famosa declaração de Derrida de que “não há nada fora do texto” (a rigor, essa passagem teria sido melhor traduzida como 'não há fora-do-texto', evitando o mal entendido de que houvesse, fora do texto, algo da ordem de um espaço vazio) é, como resultado dessa leitura metodológica, erradamente entendida como significando "que a linguagem representa a realidade apenas de forma imperfeita”. A linguagem, é claro, não representa a realidade de forma perfeita nem imperfeita, na medida em que o vocabulário de Derrida, e especialmente o seu conceito de escritura (DERRIDA, 1967a), anulam a oposição linguagem/realidade.

Para de Ville (2011), as leituras que associam Derrida com algo sob o título de "pósmodernismo” ou “pós-modernidade” também falham em traduzir seu pensamento. Afinal, já vimos que Derrida não considera possível simplesmente virar a página sobre a tradição, e isso inclui, é claro, a modernidade. De certo modo, a desconstrução, ao mesmo tempo que se opõe à modernidade, radicaliza alguns dos seus princípios, como obviamente é o caso do princípio da dúvida diante de todo dogma. Esse princípio é voltado contra a própria modernidade, mostrando que ela própria tem seus dogmas - da razão, do sujeito, do Estado. “As noções de verdade, correção e precisão,” ressalta de Ville (2011, p. 7, tradução nossa), “não são abandonadas por Derrida, mas reinscritas”, de modo que não se trataria de simplesmente assumir o senso comum "pós-modernista” de que, não havendo verdades absolutas, toda interpretação é puramente subjetiva. "Derrida, e Heidegger antes dele,” lembra de Ville (2011, p. 7, tradução nossa), “clara e convincentemente mostraram que esse ponto de vista é fundado na metafísica da presença, e mais especificamente na ilusão da presença a si mesmo do sujeito”, para afinal afirmar que, na ausência de verdade objetiva, um sujeito é livre para interpretar como bem entende, é preciso ainda de um sujeito livre e autodeterminado, com um ponto arquimediano a partir do qual decidir. Na contramão disso, o pensamento de Derrida - como, aliás, os da maioria dos filósofos importantes chamados “pósmodernos” - não permite tal concepção isolada do sujeito, ou sua separação clara em relação a um

\footnotetext{
${ }^{5}$ Expressões como "pós-moderna”, “pós-modernidade” e "pós-modernismo” não seriam rigorosas para o contexto da nossa discussão, seja referindo-se a uma vertente de pensamento (que, em muitos casos, seria melhor descrita pela expressão “pós-estruturalismo”), seja para referir-se a uma era histórica. Como veremos, Derrida não considera seu próprio pensamento pós-moderno, nem considera que a humanidade encontre-se em uma era já removida da modernidade. A expressão, contudo, aparece aqui (usada por de Ville) para referir-se a uma certa recepção, a nosso ver equivocada, do pensamento de Derrida, que utilizou-se dessa denominação.
} 
objeto. Desse modo, a leitura "pós-moderna” de Derrida, pensando superar a modernidade, na verdade configura-se em leitura metafísica da desconstrução.

A leitura que de Ville chama ético-liberal, por sua vez, corresponde a alguns pontos já discutidos aqui. “Nessa versão”, escreve de Ville (2011, p. 8, tradução nossa), “podemos dizer que a justiça, que é entendida como o (total) reconhecimento da pluralidade dos interesses, é tragicamente impossível”. Essas leituras, que fariam por vezes uma apropriação demasiado levinasiana do pensamento de Derrida sobre a justiça (ignorando o fato de que Derrida não simplesmente toma o conceito de justiça de Lévinas e sim, como de praxe, o desconstrói ${ }^{6}$, a fim de mitigar seu teor metafísico), acabariam, assim, não capturando o quanto a noção de alteridade (que não poderemos discutir aqui a fundo) é pervasiva no pensamento de Derrida. Leituras de tal tipo seriam as que, adaptando a desconstrução à boa consciência de uma ética liberal, a domesticam, retirando dela sua força contrária ao direito.

De Ville (2011, p. 9, tradução nossa) escreve ainda que “outros, adotando uma leitura similar [liberal] de Derrida, criticaram essa 'ética desconstrutiva da diferença’ por tornar impossível a avaliação de pretensões incompatíveis”. De Ville se refere, por exemplo, ao caso de Rosenfeld (2009), que, ao tratar a questão do terrorismo, considera que a "ética da diferença” de Derrida seria “incapaz de lidar com o problema do terrorismo” (o que, na sua ótica, parece significar fornecer uma condenação fundamentada do terrorismo). Rosenfeld analisa tanto uma "ética da identidade", de modelo kantiano, quanto essa "ética da diferença”, e conclui que cada uma peca por exacerbar-se em uma direção oposta. Como via média, Rosenfeld (2009, p. 838, tradução nossa) defende uma "ética da pluralidade”:

\begin{abstract}
A vantagem de uma ética pluralista é que, ao mesmo tempo que seriamente almeja a acomodar a diferença, ela se recusa a tratar a singularidade irredutível como um absoluto, assim evitando as carências [shortcomings] da ética da diferença derridiana. [...] Argumentarei que [uma ética pluralista] oferece a melhor e mais sistemática [optimal and most systematic] condenação do terrorismo global, consistente com a busca pelo melhor equilíbrio possível entre identidade e diferença.
\end{abstract}

Não caberá analisar tal argumento no detalhe, mas seus termos tornam difícil compreender por que é que o pensamento de Derrida é explorado pelo autor, se suas premissas e objetivos parecem tão distantes dos da desconstrução. Causa espanto considerar uma "shortcoming" da "ética da diferença” o fato de que ela não fornece "a melhor e mais sistemática condenação do terrorismo global”, finalidade alienígena ao pensamento de Derrida. Medir o sucesso ou fracasso da desconstrução pelo seu poder de fundamentar uma conclusão assumida de antemão (a de que o

\footnotetext{
${ }^{6}$ Ver, por exemplo, DERRIDA, Jacques. L'écriture et la différence. Paris: Éditions du Seuil, 1967b.
} 
terrorismo global deve ser condenado) é algo difícil de compreender. Não porque a desconstrução fosse impedir-nos de condenar o terrorismo global - ela certamente não iria. Mas não se trata, nunca, para o pensamento de Derrida, de decidir sobre o que é ou não condenável. Ademais, todo o discurso em torno de propostas “melhores e mais sistemáticas” e "busca pelo melhor equilíbrio possível” é remanescente de um pensamento "liberal” cuja boa consciência (a ideia de que possamos ir dormir o sono dos justos, acreditando ter chegado à “melhor solução” ou ao "melhor equilíbrio possível” diante de um problema complexo como o do terrorismo) se opõe diametralmente a tudo o que tem a ver com a desconstrução. O mero fato de medir a desconstrução por tais critérios já mostra que temos uma leitura liberal, metafísica, que não procura desconstruir o equilíbrio, mas estabelecê-lo e conservá-lo tão estável quanto possível.

Como é característico de uma leitura liberal, Rosenfeld (1992, p. 168, tradução nossa) fala da “incorporação [incorporation]” da desconstrução pelo direito, alegando que "o direito apresenta as duas condições que o autorizam [entitle] legitimamente a acolher [embrace] a desconstrução”. Ainda que argumentando no mesmo sentido que nós estaríamos argumentando neste artigo - para uma introdução da desconstrução no âmbito do direito -, todo o vocabulário de que o autor lança mão (condições, autorização, título, legitimidade) está ligado à força conservadora do direito, e não à desconstrução. A pertinência de um discurso desconstrutivo, como já vimos, não está na sua adequação a um campo, mas na sua inadequação; não na sua simples legitimidade, mas em uma desestabilização de toda legitimidade. Em momentos como esse, fica clara a domesticação em curso, quando se pretende acolher a desconstrução de uma forma segura, regulada, contida e inofensiva.

Semelhantemente, Rosenfeld (2009, p. 820, tradução nossa) afirma que o pensamento de Derrida "engrena bem [meshes well] com correntes importantes na teoria jurídica americana como os Critical Legal Studies e o pragmatismo”, embora trace uma separação interessante entre desconstrução e Critical Legal Studies ao argumentar que "tanto para os CLS quanto para Derrida a justiça é impossível, embora para os CLS ela seja impossível devido a relações de poder prevalentes, enquanto para Derrida a justiça é impossível por razões ontológicas”, e acrescenta: “mas apenas para Derrida é um dever buscar a justiça como se fosse possível e necessária”. Já vimos, por outro lado, a crítica de de Ville a esse ponto da leitura liberal de Derrida, para a qual a justiça seria simplesmente impossível, enquanto em Derrida a distinção entre possibilidade e impossibilidade não pode ser mantida estável.

Antes de continuarmos à última modalidade de leitura descrita por de Ville - com a qual o autor parece ter maior afinidade -, caberia incluir a ressalva, feita por ele, de que seu objetivo não é 
encarnar uma polícia da correção, separando leituras corretas e incorretas de Derrida, ou pretendendo que haja um verdadeiro Derrida, uma verdadeira leitura de Derrida, a ser definida e separada das leituras incorretas. Nada disso faria sentido tendo como ponto de partida a desconstrução. Mas acreditamos que de Ville (2011, p. 7, tradução nossa) está mais uma vez bem encaminhado quando argumenta que seu livro "não é sobre clamar um direito de propriedade sobre Derrida, mas precisamente sobre insistir na força de expropriação dos seus textos”. O que estivemos tentando fazer, até aqui, não é afirmar que haja uma única leitura possível da obra de Derrida, mas sim manter um outro tipo de fidelidade à sua obra, que tem a ver justamente com uma certa consciência sobre o fechamento de um discurso. Perceba-se que, desde o início, não se procurou aqui dar nenhuma definição correta da desconstrução, mas apenas mantê-la em curso, manter o trabalho da desconstrução justamente impedindo que se consolide. Manter em curso a desconstrução de todo discurso de autoridade que pretenda se legitimar a respeito da desconstrução, de toda tradição de pensamento que pretenda estabelecer-se sob o nome da desconstrução, é a única postura (paradoxalmente) fiel à desconstrução que se pode ter nesse assunto. Não se trata, portanto, de separar leituras corretas de leituras erradas, mas de forçar em todos esses discursos uma certa abertura. A própria leitura proposta aqui é desconstrutiva, no sentido de que ela deve desestabilizar os pressupostos dos textos sobre os quais se debruça. Como esses textos estabelecem seus próprios compromissos com a obra de Derrida, é evidente que parte dessa desestabilização terá a ver com a relação que nutrem com essa obra. Por exemplo, um pensamento que se pretende desconstrutivo inclui, presume-se, um compromisso de vigilância diante do fechamento dos discursos sobre si mesmos. Quando tal pensamento, ele próprio, se fecha, passa a ser objeto passível de desconstrução, num sentido que não deriva puramente da sua autoconcepção como pensamento desconstrutivo, nem puramente de uma "aplicação externa" da desconstrução sobre ele, e sim complica a divisão entre o interno e o externo.

Continuemos, então, à última leitura do pensamento de Derrida no contexto anglosaxônico, a que de Ville (2011, p. 10, tradução nossa) dá o nome de leitura cosmopolita, e que ele relaciona com a “importante e singular contribuição de Douzinas”, um dos principais representantes da versão britânica da teoria jurídica crítica. Para de Ville, ao tratar a noção de "democracia por vir" e a leitura que Derrida faz de Marx, Douzinas “admiravelmente vai além das leituras éticas liberais recém-analisadas.” Para de Ville, o livro de Douzinas, Human Rights and Empire, “expõe e resiste, como Derrida (além de Foucault e outros), o caráter (ainda) totalitário das democracias liberais.” E ainda assim, apesar de todos os elogios, Douzinas tampouco é poupado: "Similarmente aos CLS nos Estados Unidos," escreve de Ville, "os paradoxos detectados por Douzinas não se transformam em 
aporias no sentido em que isso acontece em Derrida. [...] A oposição (metafísica) entre o particular e o universal - isto é, entre presença e representação - [...] permanece [em Douzinas]”.

De Ville (2011, p. 12, tradução nossa) acredita que "essa retenção de um discurso no interior da metafísica vai quase inevitavelmente levar a conflitos, em longo prazo, na fundação de uma política jurídica de esquerda radical”. Se isso é verdade, e se, como vimos, todas as modalidades de leitura (metodológica, liberal, pós-moderna, cosmopolita) descritas pelo autor de uma forma ou de outra se mostram metafísicas, então uma política desconstrutiva radical ainda está por ser fundada no âmbito jurídico (ainda que seja difícil dizer exatamente no que consistiria tal política desconstrutiva). Para de Ville (2011, p. 8, tradução nossa),

\footnotetext{
Se mais atenção fosse dada às nuances do pensamento de Derrida do que aconteceu até agora, poderia ser desenvolvida uma concepção do direito que pudesse (em alguma medida) exceder a metafísica com sua economia circular. Qualquer pessoa que se importe com a justiça e com a responsabilidade ética não tem muita escolha além de enfrentar o desafio radical posto pelos textos de Derrida.
}

A desconstrução, ainda hoje, apresenta-se como um desafio, como um desafio ainda à frente, ainda por ser enfrentado, e como um desafio, inclusive, político. Se ainda não vemos uma política desconstrutiva radical no direito, é porque, a despeito das leituras ético-liberais e das radicalmente políticas, o potencial ético e político radical da desconstrução ainda não se mostrou satisfatoriamente. Esse potencial de uma responsabilidade ética radical deve abrir o espaço da ética justamente ao problematizar toda separação violenta entre possibilidade e impossibilidade, toda normatização e regulamentação que pretenda eximir o agente de uma decisão responsável. A pesquisa em que este artigo se insere tem, entre seus objetivos, inquirir esse potencial da desconstrução como pensamento de consequências éticas e políticas, que possibilite pensar uma ação política responsável em relação ao direito.

\section{CONCLUSÃO}

No decorrer deste artigo, procuramos apresentar criticamente a recepção do pensamento de Jacques Derrida nos estudos jurídicos, a partir de alguns exemplos destacados de sua discussão no mundo de língua inglesa. Nesse percurso, apresentamos a desconstrução como pensamento que recusa classificações e metodologias. Fornecemos uma série de definições oblíquas, parciais e temporárias da desconstrução, muitas vezes mais negativas do que positivas, dizendo apenas o que a desconstrução não é. Esperamos, porém, que ao longo do caminho tenha ficado clara a razão de um tratamento tão oblíquo: qualquer definição da desconstrução a inseriria em um discurso fechado e estável, quando sua característica é justamente de abrir e desestabilizar todos os discursos. Vimos, a 
partir da classificação proposta por Jacques de Ville, como grande parte das leituras da desconstrução, sejam “pós-modernas”, ético-liberais, metodológicas ou cosmopolitas, de uma forma ou de outra recaem em algum tipo de fechamento metafísico do discurso, domesticando a desconstrução. Fizemos críticas aos Critical Legal Studies, na medida em que estes instrumentalizaram a desconstrução como método aplicável a causas políticas predeterminadas, bem como às leituras de matiz político liberal-democrático que domesticam o pensamento de Derrida. Assim, chegamos à conclusão que o pensamento da desconstrução, com sua implicação de responsabilidade ética e política radical, ainda se apresenta como um desafio a ser enfrentado pelo pensamento crítico do direito - não porque sua recepção não tenha sido “correta” ou "adequada” em relação a uma leitura originária de Derrida, mas porque muitas vezes essa recepção acabou se consolidando em formas elas mesmas passíveis de desconstrução.

Gostaríamos, assim, de encerrar reiterando a afirmação do terreno da responsabilidade política e da relação entre direito e violência como campo em que os desdobramentos radicais da desconstrução ainda poderão ser proveitosamente analisados nos estudos jurídicos. Em trabalhos ainda por vir, buscaremos avançar o projeto de pensar o direito a partir dessa responsabilidade política radical, e de vigilância constante à questão da violência, tanto física quanto interpretativa, e inclusive no ponto em que as duas classificações se confundem.

\section{REFERÊNCIAS}

BALKIN, Jack. Decontruction's Legal Carreer. In: Cardozo Law Review, v. 27, n. 2, 2005. Disponível em: <http://goo.gl/TU9MIz>. Acesso em: 24 out. 2015.

BENNINGTON, Geoffrey. Derridabase. In: BENNINGTON, Geoffrey; DERRIDA, Jacques. Jacques Derrida. Chicago: University of Chicago Press, 1993.

CRITCHLEY, Simon. Derrida Among the Philosophers. In: GOODRICH, Peter et al. Derrida and Legal Philosophy. London: Palgrave MacMillan, 2008, p. 21-32.

DERRIDA, Jacques. De la Grammatologie. Paris: Éditions de Minuit, 1967a.

. Force de Loi: Le “fondement mystique de l’autorité”. Paris: Galilée, 2005.

. L'écriture et la différence. Paris: Éditions du Seuil, 1967b.

. Marges de la Philosophie. Paris: Éditions de Minuit, 1972.

. Negotiations. Stanford: Stanford University Press, 2002.

DE VILLE, Jacques. Jacques Derrida: Law as Absolute Hospitality. Nova York: Routledge, 2011. 
DOUZINAS, Costas; GEAREY, Adam. Critical Jurisprudence: The political philosophy of justice. Oxford: Hart Publishing, 2005.

DOUZINAS, Costas. Violence, Justice, Deconstruction. In: German Law Journal, v. 6, n. 1. 2005, p. 171-178.

DUQUE-ESTRADA, Paulo César. Alteridade, violência e justiça: trilhas da desconstrução. In: DUQUE-ESTRADA, Paulo César (Org.). Desconstrução e ética: ecos de Jacques Derrida. Rio de Janeiro: Editora PUC-Rio, 2004, p. 33-64.

. Introdução. In: DUQUE-ESTRADA, Paulo César (Org.). Desconstrução e ética: ecos de Jacques Derrida. Rio de Janeiro: Editora PUC-Rio, 2004, p. 7-8.

FISH, Stanley. Europe in America, part 1. New York Times, 2008. Disponível em: <http://goo.gl/oTM5qD>. Acesso em: 24 out. 2015.

GOODRICH, Peter. Europe in America: Grammatology, legal studies, and the politics of transmission. In: LEGRAND, Pierre (Org.). Derrida and Law. Burlington: Ashgate Publishing Company, 2009, p. 257-308.

HADDOCK-LOBO, Rafael. Derrida e o labirinto de inscrições. Porto Alegre: Zouk, 2008.

LÈBRE, Jérôme. Jacques Derrida: La Justice sans Condition. Paris: Michalon Éditeur, 2013.

ROSENFELD, Michel. Deconstruction and Legal Interpretation: Conflict, indeterminacy and the temptations of the new legal formalism. In: CORNELL, Drucilla; ROSENFELD, Michael et al. (Ed.). Deconstruction and the Possibility of Justice. New York: Routledge, 1992, p. 152-210.

Derrida's Ethical Turn in America: Looking back from the crossroads of global terrorism and the Enlightenment. In: LEGRAND, Pierre (Org.). Derrida and Law. Burlington: Ashgate Publishing Company, 2009, p. 477-508.

WITTGENSTEIN, Ludwig. Tractatus Logico-Philosophicus. New York: Routledge, 1974.

\title{
THE RECEPTION OF DECONSTRUCTION IN LEGAL STUDIES: A CRITICAL ANALYSIS
}

\begin{abstract}
This paper describes the reception of Jacques Derrida's thought, known under the title “deconstruction", in legal studies. As the reception of Derrida's thoughts had its place mainly in English language academia, it is through the discussion of a selection of notable authors in that tradition that this paper develops. We adopted deconstruction as a form of reading and writing, while questioning the possibility of making it a method in the strict sense. We begin by introducing the notion of deconstruction. We discussed different modes of deconstruction's reception in legal studies, such as Critical Legal Studies and other, more liberal authors. Finally, we observed that this reception, in many cases, incurred in problems, becoming itself an object to deconstruct. That being given, we concluded that deconstruction therefore remains as a challenge to the field of legal studies. Finally, we call attention to the deeply ethical and political character of that challenge.
\end{abstract}




\section{KEYWORDS}

Deconstruction. Jacques Derrida. Law. Violence. Critical theory.

Recebido: 2 de dezembro de 2015

Aprovado: 29 de março de 2016 